\title{
Narrativa e moçambicanidade: uma ponte possível de afectos entre duas gerações
}

\author{
Lucílio Manjate \\ Universidade Eduardo Mondlane (Maputo)
}

\begin{abstract}
RESUMO: ESTE TEXTO ANALISA COMPARATIVAMENTE A PROSA DE DUAS GERAÇÕES DE ESCRITORES MOÇAMBICANOS REVELADAS NO PERÍODO DE 1975 A 1992 (ANOS DA INDEPENDÊNCIA E DOS ACORDOS GERAIS DE PAZ EM MOÇAMBIQUE, RESPECTIVAMENTE) E QUE MARCARAM PROFUNDAMENTE A LITERATURA MOÇAMBICANA. CONSIDERANDO QUE A GERAÇÃO DE 75 É PROFUNDAMENTE MARCADA PELAS VICISSITUDES DA COLONIZAÇÃO, ENQUANTO A GERAÇÃO DE 92 É MARCADA, SOBRETUDO, PELO DRAMA DA GUERRA DOS DEZASSEIS ANOS, PROCURÁMOS ENTENDER COMO E COM QUAIS INDAGAÇÕES ESTES ESCRITORES PRODUZEM UM DISCURSO IDENTITÁRIO.
\end{abstract}

ABSTRACT: THIS PAPER ANALYZES COMPARATIVELY THE PROSE BY TWO GENERATIONS OF MOZAMBICAN WRITERS THAT WERE REVEALED IN THE PERIOD OF 1975 TO 1992 (YEARS OF INDEPENDENCE AND THE GENERAL PEACE AGREEMENT FOR MOZAMBIQUE, RESPECTIVELY) AND WHICH DEEPLY MARKED THE MOZAMBICAN LITERATURE. TAKING INTO CONSIDERATION THAT THE GENERATION OF '75S IS DEEPLY MARKED BY THE VICISSITUDES OF COLONIZATION, WHILE THE GENERATION OF '92S IS MARKED MAINLY BY THE TRAGEDY OF THE SIXTEEN YEARS WAR, WE SEARCH TO UNDERSTAND IN WHAT MANNER, AND WHAT QUESTIONS THESE WRITERS ASK WHEN PRODUCING A DISCOURSE OF IDENTITY.

PALAVRAS-CHAVE: DUAS GERAÇÕES DE ESCRITORES, DISCURSO IDENTITÁRIO, COLONIZAÇÃO, GUERRA DOS DEZASSEIS ANOS.

KEYWORDS: TWO GENERATIONS OF WRITERS, DISCOURSE OF IDENTITY, COLONIZATION, THE SIXTEEN YEARS WAR. 


\section{ntrodução}

No estudo das Literaturas Pós-coloniais uma das questões principais - senão a principal - para a qual os estudiosos têm procurado resposta tem a ver com a natureza dos mecanismos que possibilitam o resgate e afirmação de um conjunto de valores de identificação dos seus povos, valores marginalizados por circunstâncias impostas pelo processo de colonização. Se é verdade que este campo de estudos permite, por um lado, a identificação dos mecanismos de construção de imagens de identidade intracontinentais (p. ex., comparando as literaturas dos países latino-americanos com as literaturas dos países africanos), por outro lado, não é menos verdade que esta tarefa passa, necessariamente, por identificar esses mecanismos no contexto das literaturas nacionais. Isto significa apreender as "aproximações" estéticas também verificáveis nos contextos dessas literaturas nacionais.

O conceito de "aproximação" pressupõe que as literaturas em causa sejam produto das mesmas condições históricas, sociais e culturais, ou seja, que os seus autores vivem ou viveram a mesma realidade, ficando assim justificadas as "apropriações" desses mesmos universos socioculturais ou imaginários. A sua projecção para a imanência textual resulta nas "aproximações" estéticas que a seguir esses autores apresentam.

Porque falamos em "aproximações", entenda-se o conceito identidade como reiteração textual, diacronicamente considerada, desses mesmos "objectos" culturais. Derrida esclarece. Segundo refere, a identidade nunca é dada, recebida ou atingida: somente permanece o processo interminável da identificação (Bernd, 2005). Para Bernd, esta identificação é indissociável da narrativa e consequentemente da literatura. A identidade como algo em contínua construção assenta nestes pressupostos.

É com base nesta narração, que é identificação, que nos propomos identificar alguns mecanismos recorrentes pelos quais os prosadores moçambicanos fazem incursões ao universo cultural moçambicano. Pretendemos estabelecer uma ponte de vozes, de tons, entre a geração de escritores que publicam depois da Independência, proclamada a 25 de Junho de 1975, e a geração que publica após os Acordos Gerais de Paz, em 1992. Com efeito, Ungulani Ba Ka Khosa e Mia Couto são os elegíveis representantes da geração de escritores do pós-independência. Aurélio Furdela, Rogério Manjate e Midó das 
Dores são, igualmente, os representantes da mais nova geração de escritores moçambicanos, uma geração que se manifesta literaria e publicamente após os Acordos Gerais de Paz (1992). As obras são, respectivamente, Orgia dos Loucos (OL), Vozes Anoitecidas (VA), De Medo Morreu o Susto (DMS), Amor Silvestre (AS) e A Biblia dos Pretos (BP).

\section{Identificação em Ungulani Ba Ka Khosa, Mia Couto, Aurélio Furdela, Rogério Manjate e Midó Das Dores}

As aproximações entre estes autores situam-se ao nível de três tópicos fundamentais:
a. A incorporação do imaginário tradicional local;
b. A recorrência a um discurso escatológico;
c. A incorporação do modelo das narrativas de tradição oral.

\subsection{A incorporação do imaginário tradicional local}

A evocação dos valores ou "objectos" culturais vinculados ao imaginário tradicional é recorrente na prosa moçambicana. Entretanto, no que a prosa também deriva da tensão entre os "objectos" próprios desse imaginário e os considerados modernos, ligados a uma certa racionalidade científica, segundo Matusse (2008), Ungulani Ba Ka Khosa e Mia Couto são, seguramente, os escritores que mais têm discutido esta questão. Considere-se o conto "Morte Inesperada", de Khosa. Neste texto, é sugestiva a renitência do protagonista da história, Simbine, em ir à escola, invocando razões já invocadas pelo avô, quando em redor do fogo que lançava chispas intermitentes à noite polvilhada de estrelas, afirmara que os pretos viveram séculos sem o quinino e o livro, e a sua geração ia de gerações em gerações, e a sua História corria na memória fértil dos velhos que habitaram estas terras antes dos homens da cor do cabrito esfolado entrarem com o barulho das suas armas, a sua língua e os seus livros (p. 68).

Note-se a aversão a todo um conjunto de "objectos" estranhos ao imaginário tradicional ou indígena, nomeadamente o quinino, o livro, o barulho 
das armas e a língua. A estes elementos contrapõem-se outros, ainda que alguns de forma elíptica, mais precisamente a vitalidade dos pretos, oposta a uma suposta fragilidade do homem branco, que o quinino representaria; a memória fértil dos pretos, oposta a uma suposta precariedade da memória do branco que o livro simbolizaria; as flechas e azagaias, armas silenciosas ("sofisticadas", afinal), contra o barulho das armas do branco; as línguas bantu, metonímias, enfim, de toda uma cosmovisão local que as mesmas veiculam, opostas à língua do branco e à sua respectiva cosmovisão.

A pretexto de não ir à escola, Simbine invoca toda esta simbologia; note-se, muito a propósito, que a expressão da corrente de consciência do Simbine pelo narrador, fazendo-o fluir, a ponto de fundir o discurso do mesmo com o do seu avô, por concordância ideológica, resgata a imagem do sábio que a figura do ancião representa. Efectivamente, como avança Secco (2008), na lógica do universo da oralidade, o ancião era o guardião da memória, o contador de estórias que passava aos mais jovens os conhecimentos tradicionais. Neste sentido, se o avô é um sábio, sem ter ido à escola, está justificada a renitência do protagonista em ir à escola, símbolo daquela sabedoria entendida à luz dessa racionalidade cientifica, aqui oposta a essa outra sabedoria, entendida à luz das leis do universo tradicional local.

Não é outra a questão colocada em "Afinal, Carlota Gentina não chegou de voar?", de Mia. História da confissão de um crime, esta tese (de que houve um crime) é que há que fundamentar. Após “descobrir” que a mulher do cunhado, irmã da sua, era feiticeira, o protagonista suspeita de que a sua também seja, visto que, segundo a tradição, sendo uma feiticeira, a outra também o é. Para certificar-se, enquanto a mulher dormia, decide deitar-lhe água fervida. Não ouvindo o mesmo grito que a sua cunhada dera, o protagonista espantase: “- Carlota, porquê não mexes? Se sofres, porquê não gritas?" (p.89).

O protagonista é acusado de ter morto a própria mulher. $\mathrm{O}$ presente da diegese é uma carta escrita ao seu advogado, a quem adverte:

Eu somos tristes. Não me engano, digo bem. Ou talvez: nos sou triste? Porque dentro de mim, não sou sozinho. Sou muitos. E esses todos disputam minha única vida. Vamos tendo nossas mortes. Mas parto foi só um. Aí o problema. Por isso, quando conto a minha história me misturo, mulato não das raças, mas de existências. (p.85) 
Aqui, em síntese, a tensão que a busca identitária nos países ex-colónias origina. O protagonista, na verdade, apresenta-se. A sua identidade é a personificação e metonímia de uma identidade ambivalente das ex-colónias africanas, de uma forma geral, e de Moçambique, muito particularmente. De facto, a um momento, diz-nos: "a minha mulher matei, dizem" (p.85). Mais adiante: "O senhor me pediu para confessar verdades. Está certo, matei-lhe" (p. 91). E, finalmente: "sou filho do meu mundo. Quero ser julgado por outras leis, devidas da minha tradição. O meu erro não foi matar Carlota. Foi entregar a minha vida a este seu mundo que não encosta com o meu... justiça só pode ser feita onde eu pertenço” (p.94-95).

Um outro conceito de justiça, que se ajuste ao seu universo tradicional, reclama o protagonista. Rejeita, portanto, a justiça cujo advogado faz de guardião, essa justiça ajustada a esse racionalismo de que já falamos.

Tanto em Manjate como em Furdela encontramos a tendência de resgatar o imaginário tradicional e reivindicá-lo. Há neles a mesma tensão entre duas ordens de pensamento, duas maneiras de encarar o mundo, duas "racionalidades".

Em "A Morte Pronunciada" (AS), a morte de Xikapeko explica-se pelo facto de o seu pai, contrariando as disposições dos espíritos, não ter sido capaz de reivindicar aquele nome para o filho perante a senhora da conservatória e permitir que ela desse ao recém-nascido o nome de Rodrigues: "Rodrigues como o poeta! Sim Rodrigues, é mais português..." (p. 32).

Como se depreende, o autor serve-se do Nome para representar a tensão entre dois imaginários distintos, um tradicional-local, ligado à ancestralidade, e outro declaradamente português e ocidental, supostamente ligado à modernidade e aos princípios da razão.

No romance $A$ Bíblia dos Pretos, de Midó das Dores, esta tensão pode ser discutida à luz da referência à lógica binária cristianismo vs. religião tradicional local. Esta é mais uma estratégia a que os prosadores moçambicanos recorrem para, por um lado, representar a tensão e ambivalência vividas por indivíduos socializados a partir de um universo local e tradicional, mas que depois assimilaram a cosmovisão ocidental trazida pela colonização, bem como, por outro lado, para significar a fórmula para instaurar a ordem nesse caos, que passa pelo resgate desse universo tradicional e religioso. Efectivamente, a felicidade dos pretos depende do resgate do culto aos antepassados ancestrais e da vivência dessa religiosidade: 
Vários curandeiros foram consultados para que a cerimonia [que anuncia aos mortos a chegada da época do canhú] tivesse lugar, pelo que se diz os curandeiros foram unânimes em que o ritual era mais do que necessário e só podia ser bem sucedido se fosse o Xai-Xai Lhamine a dirigir todo ritual, era o único descendente do fundador da cidade de Xai-Xai, para além de que por ordem dos mortos tinha sido posto o seu nome, Xai-Xai Lhamine reunia as duas condições mais importantes para dirigir o ritual do canhú e a prece com vista a pedir paz e reconciliação com os mortos irados, escorria em suas veias o sangue puro e incorruptível do ancestral mais antigo e herdara por exigência dos defuntos o seu nome, pois vários curandeiros revelaram quando ele nasceu que se lhe colocassem um nome dos brancos todas as mulheres desta terra parariam de conceber, e para mostrar que era verdade conta-se que todas mulheres próximas da família sagrada ficaram com os sexos fechados durante uma semana, sem saber como e sem poder urinar tão pouco gozar dos prazeres da noite, foi assim que ficou Xai-Xai Lhamine, e mesmo depois de se converter à religião católica não ousou adoptar o nome dos santos, havia um grande problema no meio disto, Lhamine hoje estava transformado em Animador da igreja, tão conhecido pela sua devoção à Deus, embora não tenha nunca destruído a Thepela, a palhota sagrada que se encontrava na sua casa, foi este facto que dificultou a realização da cerimónia, pois Lhamine teve que renunciar ao cargo na igreja e à própria religião para atender ao chamamento dos defuntos e do regresso às leis da tradição, não foi fácil, houve reuniões e reuniões entre os anciãos, curandeiros e o escolhido, até que finalmente o velho Tango anunciou que os defuntos estavam dispostos a punir o seu filho por oprobriar o caminho da verdade, apenas foram necessárias duas provas do poder dos defuntos para Lhamine renunciar ao cristianismo com um vexame dobrado, primeiro escorregou e caiu como ninguém nas escadas do altar em plena missa, embora não se tenha magoado sentiu os espinhos na vergonha pois as calças se rasgaram e denunciaram a sua cueca que como se diz não era nada decente para um animador, todavia foi a diarreia do ar, como a chamam as pessoas, que o fez seguir a vontade dos mortos, a diarreia do ar é uma doença estranha que começou a atacar o animador um tempo após aquela hedionda oração do Cristo Negro no altar da igreja, cada vez que se põe em frente da comunidade para cantar, pregar, fazer leituras sente uma violenta necessidade de cagar ... foi então que o animador percebeu que não podia se lutar com os mortos e renunciou a tudo e aceitou dirigir a cerimónia da chegada do canhú. (p. 70-71) 
Apesar de ainda não termos feito referência à obra de Furdela, por razões de organização expositiva, se bem que podemos considerar que, efectivamente, as estratégias técnico-literárias e semântico-ideológicas que esta geração mais recente apresenta aproximam-se das da geração que os antecede, pela tensão que representam e pela reivindicação que fazem, há, igualmente, que questionar como é que esta tensão é resolvida. Parece-nos que esta tarefa passa por considerar o discurso escatológico que em ambos se ouve. Porque estrutura e funcionalmente conexionados, importa também considerar a incorporação do modelo da narrativa oral.

\subsection{O discurso escatológico e o modelo das narrativas orais}

Por escatologia entenda-se, na acepção de Noa (1998), discurso da irreversibilidade do destino e do esvaimento da própria existência, associado a um fatalismo ancestral enraizado na tradição, às superstições e profecias.

Voltemos ao texto "A Morte Pronunciada" (AS). Considere-se o seguinte: perante a senhora da conservatória, se, por um lado, o pai de Xikapeko lembra o facto de o nome do filho ter sido escolhido pelos espíritos, o que é confirmado pelo curandeiro após a morte da criança, a senhora da conservatória evoca o que pode considerar-se símbolo da portugalidade, pelo que quer a criança portuguesa. O facto de o pai de Xikapeko lembrar que os espíritos não gostariam de o nome ter sido trocado (p. 32), para além de indiciar a morte da criança, quando oposto à insistência da senhora da conservatória em colocar-lhe o Nome de Rodrigues, abre um parêntesis para um debate sobre o que se convencionou chamar superstição. Efectivamente, na perspectiva da senhora da conservatória, fica implícito que parece razoável, racional, e uma atitude que beneficiaria a criança, como a de atribuir-lhe o nome de Rodrigues. Sem descurar que temos neste texto o retrato de um tempo-espaço colónial, com a correspondente ideologia veiculada, subjaz nesta atitude da senhora da conservatória a crença no beneplácito de Xikapeko, não necessariamente de tais virtudes poéticas (note-se a referência ao poeta Armindo José Rodrigues, século XVIII), mas antes dos valores que integram a noção de portugalidade, valores tais que confeririam a cidadania portuguesa a Xikapeko. Entretanto, esta razão falha exactamente porque, embora permaneça no plano do implí- 
cito, a crença num tal beneplácito de virtudes pode entender-se como a razão que levou a que o pai de Xikapeko desse este nome ao filho, conforme as disposições dos espíritos, pese embora o facto de não poder recusar. Mas seria exactamente esta impossibilidade de recusar a explicação para a sua crença. Isto demonstra que a questão aqui subjacente é análoga àquela da senhora da conservatória, ou seja, o pai de Xikapeko, por seu turno, crê nos valores que integram a consciência que tem de pertencer à sua comunidade. Extensivamente, é a crença nos valores que integra a noção de moçambicanidade, os mesmos valores que confeririam a cidadania moçambicana a Xikapeko.

Tanto a senhora da conservatória como o pai de Xikapeko movem-se por simples crenças (ambos evocam antepassados), a superstição, definida como sendo "uma crença ou conjunto de crenças estranhas à fé religiosa e contrárias à razão, sem fundamento positivo conhecido, mas suficiente para determinar um meio de conduta, com abstenções ou acções que têm por fim evitar o nefasto e assegurar o benéfico" (Grande Enciclopédia Portuguesa e Brasileira, Vol. 30, p. 370), quando evocada pejorativamente, como aliás é comum, não passaria de uma forma etnocêntrica de olhar e entender o Outro.

Apesar de fracassada a reivindicação do pai de Xikapeko, a partir do seu comportamento, há, efectivamente, registre-se, um projecto de legitimação dos "objectos" próprios da cosmovisão local por meio do desmoronamento de preconceitos que, uma vez destronados, deixam a nu que os "objectos" culturais, no amplo campo das relações interculturais vividas em países excolónias, funcionam como manipulações visando a proclamação de hegemonias culturais.

Reivindicar e legitimar os "objectos" próprios da cultura local é o que subjaz igualmente aos contos de Khosa, Mia e Furdela.

Inesperada em Khosa, pronunciada em Manjate, o diálogo da morte entre os dois instala-se e prossegue. A ideia da irreversibilidade do destino constróise a partir do momento em que se percebe que tanto a morte de Xikapeko como a do Simbine, tendo sido ao longo dos textos indiciadas formal e semanticamente (são os títulos, é a traição a um conjunto de valores culturais, são as profecias: da mãe do Simbine ao tentar persuadi-lo a ir à escola: "Terás uma morte maldita, filho..." (p.68), e do pai de Xikapeko, ao reivindicar o nome do filho perante a senhora da conservatória: "Nada - para o pai qualquer nome não podia ser - Senão espíritos zangar" (p.32), funcionam como 
punição por terem transgredido as regras do modus vivendi da comunidade. Por isso as estruturas das diegeses aproximam-se à do tipo Advertência $\rightarrow$ Trangressão $\rightarrow$ Punição, do modelo das narrativas orais do tipo descendente, em que, segundo Matusse (1998), o protagonista comete uma transgressão às normas vigentes na sua comunidade para dai obter benefícios, acabando, no entanto, por ser punido por essa mesma transgressão.

Em "Afinal, Carlota Gentina não chegou de voar", instalada, como vimos, a tensão entre os dois mundos, fica no protagonista, e no leitor, pelo facto de a composição ser aberta, o eterno desejo de regressar à casa, porque "fora de casa sempre faz frio" ( p.94).

Interessante forma de enfatizar a urgência do debate, a urgência de encontrar uma saída, porque:

"Sou um cego que vê muitas portas" (p.95)

"O feitiço é mal das irmãs, doença das nascenças" (p.94).

A escatologia, em Mia, também liga-se a esse fatalismo ancestral enraizado na tradição e nas superstições. A tese que citámos, porque proverbial (e é o móbil do "crime" enraizado no universo da tradição local), é temporalmente transversal, o que, relacionada com a natureza aberta da narrativa, perpetua esse debate urgente já aludido, que não é senão a imagem fatalista de um Moçambique refém desta ambivalência identitária. Há aqui, igualmente, a recuperação aproximada do já referido modelo das narrativas orais. Efectivamente, o protagonista sofre por ter traído o modus vivendi da sua comunidade: " $\mathrm{O}$ meu erro não foi matar Carlota. Foi entregar a minha vida a este seu mundo que não encosta com o meu" (p.94).

O mesmo acontece em "A morte de Jowawa" (DMS), de Furdela. A morte do protagonista cumpre aquele papel de legitimação e valorização dos valores ligados ao universo tradicional.

Jowawa fora ao curandeiro pedir um tratamento a fim de que, quando fosse à África do Sul, obtivesse sucedido. Por não ter cumprido com as orientações do curandeiro (não calçar sapatos, pelo menos até chegar à África do Sul), morreu.

Jowawa descuidou-se e a profecia do curandeiro realizou-se. Há aqui, como se observa, a recuperação completa do modelo das narrativas orais acima 
descrito. A punição cumpre aqui aquela função de reivindicar e legitimar o tradicional-local. Efectivamente, se a profecia do curandeiro (personagemsímbolo do universo tradicional), de que se o sono do Jowawa viesse a revelar-se mais sorrateiro que a sua atenção as consequências não respeitariam limites, se efectivou porque Jowawa acabou adormecendo com os sapatos aos pés (o sapato, objecto radicalmente estranho ao universo tradicional do protagonista, diga-se), a sua morte não só resgata a importância do curandeiro, como também legitima e valoriza, metonimicamente, a correspondente sabedoria e tradição. Como no caso da Morte Inesperada, de KHosa e da Morte Pronunciada de Majante, a escatologia em Furdela resulta do facto de as punições serem profeticamente indiciadas.

$\mathrm{Na}$ citação do romance de Midó, percebe-se que Xai-Xai Lhamine sofre, gradativamente, as consequências de não prestar culto aos seus antepassados ancestrais e de se converter à religião cristã. Aqui a evocação desse momento fundador da perdição e angústia das ex-colónias a que o romance se refere, a chegada do Cristianismo ao serviço da implantação do colonialismo nos paises africanos. Tal como acontece com os outros autores aqui discutidos, em Midó, a saída para esse caos passa pelo resgate desse universo identitário primário, local e tradicional.

\section{Das aproximações utópicas}

Perpassa, nestes textos, a ideia de que é preciso reivindicar e legitimar os valores e a ordem próprios da(s) cultura(s) local, a ideia de que é preciso regressar a esse tempo e espaço idílico, resgatar esse mundo de calma e de harmonia, de naturalidade e de silêncio, de simpatia humana e de expansão anímica (Lares, 1970). Esta é a razão por que designamos estas aproximações como utópicas; há a busca ou tentativa de resgate de uma concepção de existência que seja alicerçada na busca e respeito pelos valores culturais locais, que são o garante de estabilidade na comunidade.

Se o desafio de países como Moçambique é o de reduzir o máximo possível as assimetrias verificáveis a todos os níveis e ao longo dos territórios nacionais (assimetrias herdadas da história colonial), garantindo que as políticas de desenvolvimeno sejam capazes de integrar todos os grupos etnolinguísticos 
não só como teorizadores de tais políticas, mas também como beneficiários das mesmas, isto passa por esta visão fraterna e comunitária da sua existência, uma visão que é de partilha, amorosa, só possível potenciando os valores culturais de cada grupo e das nações em geral como valores que favorecem essa integração e caminhada.

\section{Em jeito de conclusão}

Se a geração representada por Mia Couto e Ungulani Ba Ka Khosa, em virtude das consequências da colonização, defende(ra)m um Moçambique fraterno, que fosse capaz de resgatar os seus fundamentos identitários, percebe-se que a geração subsequente, devido ao drama da guerra dos 16 anos que devastou o país, reinventa aquele discurso mítico do eterno regresso à casa. Percebe-se, então, que o projecto é comum, pois esse regresso significa identificação e exaltação dos valores ou "objectos" que caracterizam a nação moçambicana. Se, por um lado, o projecto é o mesmo, por outro, paradoxalmente, a noção de moçambicanidade enquanto ambivalência, tensão, hibridismo cultural se afirma como um projecto comum a outro: a sua narração ou teorização, exactamente pela lógica diacrónica em que se inscreve.

\section{Referência Bibliográfica}

BERND, Zilá, (2005), Literatura e Identidade Nacional. 2a. ed. Porto Alegre: UFRGS EDITORA.

COUTO, Mia, (1987), Vozes Anoitecidas, Lisboa: Caminho.

DURANTI, Alessandro, (1997), Linguistic Anthropology. New York: Cambridge University press.

FURDELA, Aurélio, (2003), De Medo Morreu o Susto. Maputo: Imprensa Universitária, UEM.

KHOSA, Ungulani Ba Ka Khosa (1990), Orgia dos Loucos. Maputo: Associação dos Escritores Moçambicanos.

LARES, Ivo (1970), "Regresso às Origens", In Brotéria cultura e informação, Lisboa: Livraria Apostolado da Imprensa.

MANJATE, Rogério, (2001), Amor Silvestre. Maputo: Ndjira. 
MATUSSE, Gilberto, (1998), A Construção da Imagem de Moçambicanidade em José Craveirinha, Mia Couto e Ungulani Ba Ka Khosa. Maputo: Livraria Universitária, UEM.

DAS DORES, Midó. A Bíblia dos Pretos. Maputo: Índico, 2008

SECCO, Carmen Lucia Tindó Ribeiro, (2008), "Representações da morte em textos literários de Angola e Moçambique”. In AMÂNCIO, Iris Maria da Costa (Org.) (2008), Africa-Brasil-África Matrizes, Heranças e Diálogos Contemporâneos, Belo Horizonte: Editora PUC Minas; Nandyala. 